\title{
Banking Risk and Operating Efficiency Measures in the Era of IT
}

\author{
Farkhanda Shamim ${ }^{1}$, Shahid W. Anjum ${ }^{2} \&$ Amal Abdel Wakil ${ }^{3}$ \\ ${ }^{1}$ College of Business Administration, University of Bahrain \& the Institute for Innovation and Technology \\ Management, Ted Rogers School of Management, Ryerson University, Toronto, Canada \\ ${ }^{2}$ College of Management, Lawrence Technological University (LTU), Michigan, USA \\ ${ }^{3}$ College of Business Administration, University of Bahrain, Bahrain \\ Correspondence: Farkhanda Shamim, College of Business Administration, University of Bahrain, PO Box: 32038, \\ Bahrain. Tel: 973-1743-8656. E-mail: fshamim@uob.edu.bh
}

Received: November 27, 2014

Accepted: December 20, 2014

Online Published: December 31, 2014

doi:10.5430/afr.v4n1p103

URL: http://dx.doi.org/10.5430/afr.v4n1p103

\begin{abstract}
On the basis that risk drivers are similar to the fundamental reasons for the establishment of e-banking (cost minimization and revenue maximization), this study examines bank risk rating drivers and the degree of e-banking in 124 Japanese financial institutions for two time periods: first period covers six years (2000-2005) of the 21st century (as an example of a less volatile market) and second period is based upon last eight years of the 20th century (as an example of more volatile market). Using a basic risk scoring model, bank risk scores are regressed against operating efficiency measures, namely cost and revenue, which are calculated using stochastic frontier approach. The results confirm that the twenty first century is very advanced in its electronic-banking actuation. There is evidence suggesting that operating costs are lower and revenues are higher when banking services are delivered through electronic means. Therefore, the results support the argument that the riskiness of the banking industry might be reduced if focus is directed to operating efficiency and then to e-banking.
\end{abstract}

Keywords: Risk, Operating efficiency, Operating costs, Banking industry, E-banking

\section{Introduction}

Internet and related technologies are more than just new distribution channels. They are also different ways of providing financial services. There is substantial evidence to suggest that e-banking is being embraced by financial institutions in developed and emerging markets to the extent that explosive growth is almost at hand. By 2008 research indicated that globally more than 50 million households banked online, which is well above the 6.8 million in 1998. This number has multiplied by 2014 because the number of households in the U.S.A. alone, who bank online, reached 69 million (Statistics Brain, 2014). The emergence of e-banking will not involve banks walking away from traditional business and the e-commerce revolution will not be suddenly reversed (Streeter, 1999 a,b). By 2002, all major North American banks have added the Internet to their service delivery channels. The Internet is eclipsing other electronic channels of delivery because of its convenience.

There are conflicting views too about e-banking development. According to Goodman (1999) although banking enterprises may have the most attractive services on good-looking Web sites, this means nothing if the infrastructure of e-banking cannot support many companies, organizations and customers wanting to conduct business.

Another problem for individual banks is how to maximize the generation of Internet revenue and how to differentiate the bank's services and products from other banks. Streeter (1999a,b) makes the point that companies may fail if they are only thinking of providing low cost transactions and if they are concerning themselves with the protection of existing business and at the same time developing e-business. Other concerns relating to privacy are apparent as the e-commerce train rolls on. The Minnesota Attorney General has threatened to sue US Bancorp for selling customer information. Another related problem is security. Cyber-crime in financial services according to Sweeney (1999) will increase. He states that the e-commerce market is currently valued at US\$43 billion of annual sales and this is expected to grow to US\$1 trillion by the year 2001. With so much money and sensitive customer information going through computer networks, there is a potential for expensive breaches in security. The most recent example is JPMorgan Chase \& Co. USA cybersecurity attack on the bank where about 76 million households were affected in 2014 summer in one of the most sweeping disclosed breaches of a financial institution. 


\subsection{Risk in Japanese Financial Markets}

This study examines bank risk rating drivers in Japan for two time periods; first period covers six years (2000-2005) of the 21st century (as an example of a less volatile market) and second period is based upon last eight years of the 20th century (as an example of more volatile market). On the basis that the risk drivers are similar to the fundamental reasons for the establishment of e-banking (cost minimization and revenue maximization), this study endeavors to draw conclusions about the risk ratings ascribed and the degree of e-banking in Japanese financial sector.

Due to globalization and the banking sector deregulation policy of the government, banking working environment in Japan has been changed in the last few years. In our understanding, Japanese banks behaved more like an emerging market bank in last century. Some key differences between the bank risks rating of two time periods (representing deregulated and regulated time periods) are as follows.

a. The economic environment in which banks operate is a more important driver of intrinsic financial strength.

b. The strength of capital and provisions is a more important element in the analysis of Japanese banks. Losses can emerge more rapidly and be more severe and banks may not be able to cover those losses out of profits and so need to rely on capital and provisions to maintain solvency.

c. Just like emerging markets, Japanese banks' ability to repay depositors is dependent on the support of national authorities during a crisis. That is, the Japanese government politics and finances have a lot to do with the banks ability to repay depositors.

Current study does not include variables that proxy for economic risk, balance sheet risk and political risk. This expansion of the-banking risk model must be very interesting and is left for future research.

A banking risk model with limited explanatory power using cost and revenue efficiencies calculated by Stochastic Frontier Approach (SFA) is selected for testing the notion that the degree of e-banking and banking risk have common drivers.

If the reasons for e-banking are accepted (on the basis of the literature) as being efficient with respect to cost and revenue, it remains for the study to test if these are significant drivers of banking risk. Conclusion might then be drawn as to the proposition that banking risk is influenced by the degree of e-banking. The literature suggests that e-banking actuation is greater in the years 2000-2005 than past period and that banking risk is lower in the latter period. The question addressed in this analysis is whether or not banking risk is affected by the degree of e-banking.

\subsection{Research Objectives}

The assumption in this study is that the degree of e-banking is substantially higher in recent years. On the basis that operational efficiency improvements might drive e-banking, as some of the literature suggests (for example, Turton, 1999; Esser, 1999; Jaleshgari, 1999a,b; Ekwueme, 2012), the objective of this study is to test the significance of operational efficiency measures as drivers of perceived banking risk in a model period of 2000-2005 and a sample period of 1992-1999. If banking risk is partially yet significantly driven by operational efficiency measures in each sample period but show a greater significance of contribution to risk reduction in the model period, conclusions may then be drawn that risk reduction is due to higher level of Internet banking practices of the banks.

In addition, if the model of e-banking is deemed to be desirable, the conclusions will also include policy implications that discuss the steps that developing countries and economies in transition must take if they are to successfully implement e-banking in the interests of greater efficiency and less risk. Clearly these steps will involve both macroeconomic and microeconomic reform in emerging banking markets.

\subsection{Research Hypothesis and Questions}

The hypothesis which is tested in this study is the degree to which e-banking affect the riskiness of banks.

According to Alhaji Abubakar Aliyu et.al. (2012) more research need to be carried out in different location and different time frame by collecting the primary data to come up to a conclusion for the impact of Information and Communication Technology (ICT) on customer service delivery and banks performance.

This research contributes to the existing literature by examining the relationship between banking risk and operational efficiencies measured by costs and earnings. That is, will e-banking create the conditions where the banks involved can maximize shareholder wealth and reduce risk to a similar or greater extent than before e-commerce was conceived?

The rest of the paper is structured as follows. Theoratical underpinning and the literature review is presented in the Section 2, the model is specified and data is elaborated in the Section 3, the research findings are analyzed in Section 
4 and the implications of the study are presented in the Section 5.

\section{Theoratical Background and Literature Review}

According to Menendez (1999) the crucial point is whether or not any company will earn enough of a return on its Internet investment to be able to meet its debt obligations. There is an uncertainty factor because Internet-based businesses are still in their development phase, and this risk factor is reflected in the risk ratings. The Internet could have an effect on banks' merger and acquisition strategies because it has created uncertainty about the value of purchasing large branch infrastructures. Moodys' $(1999 \mathrm{a}, \mathrm{b}, \mathrm{c})$ feel that the implications of the Internet for retail banking could be quite profound but the effects will not harm USA bank creditworthiness at least over the next few years. Despite this concern, the study by Aliyu et.al. (2012) concluded that enhancing ICT in the banking industry is a must in a rapidly changing market place, as the ICT revolution has set the stage for exceptional increase in financial activity across the globe.

Another risk of retail banking is the loss of loyalty of customers through the convenience of Web shopping and many are offering premium rates of interest on deposits as they invest heavily in Internet systems. To some extent their worries may not be warranted because of the difficulty and disruptiveness of changing bankers. Generally speaking the profits of USA retail banks should hold up on retail deposits. Web-based competition on mortgage loans, car loans and credit cards is also increasing but at the moment the feeling is that because such margins are modest there will not be a large impact on profitability in the medium term. There is, according to O'Connell (2000), a looming threat from brokers who are chasing the higher-end customers and offering higher interest rates on deposits and in view of the end of the Glass Steagall Act restrictions brokers can now offer a broader range of banking services to their clients.

Despite the uncertainty about e-banking the foregoing literature confirms that USA banking system is one of the leaders in e-commerce and e-banking and innovation. However, recent evidence suggests that the current growth rates of e-banking in European banks exceed those of the USA (Nolan, 1999). Moodys' (1999a,b,c) reported that Sweden and Denmark are the most advanced countries in terms of progress and penetration into banking systems. Fast growth is also occurring in the UK and Germany. Then countries such as Italy, France and Spain are mentioned. As far as Asian countries are concerned, Xiusheng et.al. (2013) concludes that compared with the banks in western developed countries, online banking in China remains relatively backward, which is intensively marked with comparatively low efficiency.

Literature further reveals that banks' investment in IT sector is huge in recent years all around the world especially developed world has invested a lot of money on information technology. For example, according to Celent (2002), larger commercial banks in the United States spent as much as $25 \%$ of their total expenses on information technology. Also, according to Mai (2012), globally financial services firms in 2013 will spend between USD 270 billion and USD 460 billion on IT. Measured as a percentage of revenues, financial services firms spend more on IT than any other industry. Banks' IT costs equal $7.3 \%$ of their revenues, compared to an average of $3.7 \%$ across all other industries surveyed. Finally, Gautam ( 2012) stated that almost all banks in India have invested in expanding and improving the information technology systems and a number of new electronic-banking services have been developed.

Regarding Japanese banks, Yamori (2005) noticed that banks' IT investment remained unchanged until the fiscal year 1999 and there is a significant increase in this type of investment afterwards. According to Financial Information System Center (FISC, 2005), only 11.1\% of surveyed financial institutions in 2002 reported that they had provided Internet banking to corporate customers, however, by 2003 percentage of banks offering Internet banking reached to $36.8 \%$. The assumption is therefore made that e-banking was substantially less advanced in Japan before 2000 .

Theodore (2000) remarks that bank risk ratings and bank analysis will increasingly focus on bank's online franchise and its sustainability in an increasingly fast moving 'market space'. A bank's future strength and performance will greatly depend on its ability and capacity to provide value by re-aggregating and tailor-making commoditizing products individually and offering these services quickly, efficiently and securely. The depth and quality of intellectual and knowledge capital and its dynamics will also be important for bank strength and performance. Banks will need to develop a "clicks" rather than a "bricks" and mortar strategy as their branches will be visited less and will generate less profit. Changes in banks' risk ratings could appear less correlated to trends in financial ratios. Large sums of money initially are needed to establish an online brand. In the short-term this will negate the benefit of lower transaction costs. Costs may make e-banking the domain of larger profitable financial institutions. Nevertheless, it is also clear that the overall medium-term objectives of e-banking relate to shareholder wealth maximization. This is achieved partially through maximization of operating efficiency by maximizing earnings 
through the maintenance and increase of for example, net interest margins and through the minimization of transaction costs and non-interest expenses. Financial institutions expect to enhance the shareholder wealth maximization objective in the medium-term through e-banking. The question arises whether they will also reduce banking risk by effective e-banking. Moodys' (1999a,b,c) seems to be of the opinion that the larger financially sound banks will. Saunders and Lange (1996) feel that banking risk is the risk of liquidity problems of a bank leading to insolvency and then to bank failure. In the 21 st century Japanese banks have acquired higher capital adequacy ratio (thus indicating lower banking risk) than those in the last decade of the 20th century.

If perceptions of riskiness of banks are reduced with increased bank operating efficiency and if e-banking establishment and innovation is driven by similar efficiency considerations, does it necessarily follow that banking risk is reduced as e-banking is implemented? This is a question that is difficult to answer because the full effects of e-banking on bank shareholder wealth maximization have yet to be fully investigated in view of the relative short space of time since the advent of e-banking and the subsequent lack of hard data to analyze.

One way to continue this study is to ascertain for each bank the proportion of bank expenditure devoted to ecommerce both now and planned. This could be regarded as a more appropriate form of analysis that would eliminate the "noise" introduced by intercompany comparisons. The literature does refer to risks that are certainly introduced with the advent of e - banking, particularly in areas of safety and security of funds, security of documentation, and confidentiality of customer information (for example, Cline, 1999a,b; Sweeney, 1999). Also, Gautam (2012) referred to the risk of customers' illiteracy on the provision of e-banking services and its effect on their profitability. especially banking industry. Similarly, the results of Salehi, et.al. (2010) indicate that customers may lack knowledge regarding e-banking which is rendered by the banking sector.

From an international perspective the risks that arise from dealing with different legal systems, exchange control regulations and political systems are also factors. However, the riskiness of banks that operate internationally is also determined by other balance sheet and accounts data such as bank liquidity and capitalisation as well as economic factors, such as trade performance, external debt, and political risk (Simpson, 1999). Political risk is the risk that external payments of a country (and thus its banking system) will be restricted due to political reasons such as strikes, riots, civil unrest, revolutions, corruption, and government misappropriation and so on. The underlying driver of political risk may be economic risk due to inadequacy of foreign exchange (Bourke and Shanmugam, 1990).

As previously mentioned, due to the limitations of the data, a partial model of banking risk is to be tested in this study using only operating efficiency measures (costs and revenue data) as the independent variables.

\section{Model and Data}

In this section, we derive a model to estimate risk and discuss data and methodology issues.

\subsection{Specification of Model (Note 1)}

On the basis of literature, we assume that Equation (1) holds.

$$
E_{e}=\alpha+\beta_{1}(\text { Cost Efficiency })+\beta_{2}(\operatorname{Revenue~Efficiency~})+\varepsilon
$$

That is, the predominant driving force of e-banking (current and expected e-banking expenditures) is the banks' efficiency in terms of cost and revenue. Ee in the above equation is the value of expected e-banking expenditure by a bank as a percentage of total operating bank expenditure. What we are saying here is that all else being equal, the higher the cost and revenue efficiencies, the greater the prospects for e-banking.

The literature (for example, Menendez, 1999; Moodys', 1999a,b,c; Theodore, 2000) also suggests that banking risk is at least partially driven by similar operating costs and revenue factors. It is proposed that ultimately international banking risk is a function of expected e-banking expenditure. Due to the limitations of the data the testing of equation (1) is not possible as specific information on expected e-banking expenditure for Japanese banks is difficult to collect. Instead, based on the above literature and theory the assumption is made that banking risk is a function of expected e-banking expenditure and thus equation (2) is derived from equation (1).

$$
S_{b}=\alpha+\beta_{1}(\text { Cost Efficiency })+\beta_{2}(\operatorname{Re} \text { venue Efficiency })+\varepsilon
$$

where $\mathrm{Sb}$ is representing bank risk. Equation (2) states that efficiency of the bank leads it to take less risky operations. Therefore,

$$
S_{b}=f\left(E_{e}\right)
$$


Equation (3) is made up of equations (1) and (2). That is, according to alternative hypothesis, as the expected expenditure for a bank's e-banking increases so the perception of the riskiness of the bank reduces.

After introducing dummy variables to account for any systematic differences in efficiency levels of the city and local banks, the equation for banking risk, which is to be estimated, is as follows.

$$
S_{b}=\alpha+\beta_{1} C E+\beta_{2} R E+\beta_{3} C I T Y+\beta_{4} L O C A L+\varepsilon
$$

Where $\mathrm{Sb}$ represents banks' risk to pay depositors and measured as capital adequacy ratio, $\mathrm{CE}$ and $\mathrm{RE}$ stand for cost and revenue efficiency estimates measured by using variable effect model of stochastic frontier approach. CITY is a dummy variable taking value 1 for city banks and 0 for all other types of banks. LOCAL, a dummy variable takes value 1 for regional banks and equal to zero, otherwise.

\subsection{Methodology and Data}

124 banks are studied for two sample periods. The selection of years in two data sets are based upon the fact that in the first period, there is no or less e-banking activity in the Japanese financial sector and in the second period, there is more emphasis on electronic/virtual banking in Japan. Our literature survey and thorough analysis of banks' annual reports suggest that year 2000 is the dividing year between no-e-banking and e-banking. Therefore 124 banks in the first time period of eight years (1992-1999) making 991 total number of observations and same banks in the second time period of six years (2000-2005) making available 731 total data points to conduct a multiple linear regression analysis.

Cost and revenue efficiency values are estimated using a fixed effect model i.e., efficiency estimates are time and bank invariant. Revenue efficiency scores are used as one of the explanatory variables in this study due to existence of possible correlation between profit and cost efficiency estimates. Capital Adequacy Ratio is used to represent risk. The higher the capital adequacy ratio, the lower the risk.

\section{Empirical Results}

As a result of testing the data in sample periods discussed in the methodology and data section, we summarize results in following tables.

Descriptive statistics is tabulated for the two data sets in Table 1. Statistics provide supporting evidence that banking risk is lower in the period of 2000-2005 as the value of capital adequacy ratio is higher for said period showing that banking industry in Japan is experiencing fewer risks in early years of 21st century. Further, the value of capital adequacy ratio is higher than 8 (a minimum requirement by BIS) in recent years. Support is also provided to the concept that cost and revenue efficiencies are higher in the time period when banks are more involved in e-banking operations.

Further testing of the significance of these results is needed before it can be concluded that e-banking is likely to be implemented where the operating costs of e-banking delivery of bank services are less than the operating costs of delivery of bank services through branch networks. This is also the case where the operating revenues associated with e-banking delivery are greater than those for bank services delivery through the branch network.

Table 1. Descriptive Statistics

\begin{tabular}{lcccr}
\hline & \multicolumn{2}{c}{$2000-2005$} & \multicolumn{2}{c}{$1992-1999$} \\
\cline { 2 - 5 } & Mean & St. Deviation & Mean & St. Deviation \\
\hline Capital Adequacy Ratio & 9.148 & 1.8316 & 7.63 & 2.326 \\
Cost Efficiency Estimates & 0.7854 & 0.1103 & 0.7748 & 0.1136 \\
Revenue Efficiency Estimates & 0.7691 & 0.1187 & 0.7641 & 0.1247 \\
\hline
\end{tabular}


Before conducting a regression analysis, we checked the existence of multicollinearity among the variables. In this study, we adopt variance inflation factor (VIF) criterion as one of the measures for multicollinearity (Note 2). It is the reciprocal of the tolerance. As the variance inflation factor increases, so does the variance of the regression coefficient, making it an unstable estimate. Large VIF values are an indicator of multicollinearity. VIF is expressed as follows:

$$
V I F_{i j}=\frac{1}{1-R_{i j}^{2}}
$$

where $\mathrm{R}_{\mathrm{ij}}^{2}$ is the coefficient of determination when the $\mathrm{i}^{\text {th }}$ explanatory variable is regressed to the $\mathrm{j}^{\text {th }}$ explanatory variable.

The values of VIF for all the explanatory variables are reported in Table 2.

Table 2. Collinearity Statistics

\begin{tabular}{lcc}
\hline & \multicolumn{2}{c}{ Collinearity Statistics (VIF Criterion) } \\
\cline { 2 - 3 } & $2000-2005$ & $1992-1999$ \\
\hline Cost Efficiency Estimate & 3.629 & 2.323 \\
Revenue Efficiency Estimate & 4.555 & 2.112 \\
Dummy for City banks & 1.276 & 1.160 \\
Dummy for Local banks & 1.545 & 1.461 \\
\hline
\end{tabular}

As a result of examining for muticollinearity, we find no multicolliniarity between variables used in this study as values of VIF between various combinations of variables are much less than 10 in both data sets.

The next step involves multiple linear regression analysis. Table 3 provides a summary and a comparison of the results for each sample where capital adequacy ratio is the dependent variable. The regression results indicate that the cost and revenue efficiencies are quite significant variables that assist in the explanation of banking risk as adjusted R-square values are $35 \%$ and $22 \%$ for the 21 st and 20 th centuries respectively. This result is in line with previous studies such as Laeven (1999).

The explanatory power of these variables is greater when applied to last data set thus indicating the importance that Japanese banks perform optimally in the first five years of new century. The results show positive relationships for both samples. That is, as cost and profit efficiencies increase, so capital adequacy ratio increase and consequently, banking risk decrease. In other words, inefficient firms are found to take on a higher level of risk. It is possible that managers of inefficient banks make loans with higher yields and higher risks in an attempt to compensate for their operating inefficiency. Furthermore, an inefficient firm, which has lower market valuation, has less to lose in taking a risky gamble than an efficient firm. Further, the dummy variables representing city banks and regional banks are highly significant for current years showing that efficient city banks and efficient regional banks are taking measures to reduce banking risk.

When the above evidence is combined with the evidence from the literature that generally supports the notion that the degree of e-banking is partly dependent on operating costs and revenues, some support could be provided for our hypothesis although this relationship needs to be properly tested. That is, the perceived riskiness of banks might be driven by the current degree of e-banking involvement. The Japanese banks collectively have a greater degree of e banking in current years and at the same time they are less risky in terms of their perceived ability to repay depositors. 
Table 3. Regression Analysis (Dependent Variable: Capital Adequacy Ratio)

\begin{tabular}{|c|c|c|}
\hline & $2000-05$ & 1992-99 \\
\hline \# of Observations & 731 & 991 \\
\hline \multicolumn{3}{|l|}{ Model Summary: } \\
\hline Adjusted R Square & 0.347 & 0.223 \\
\hline \multicolumn{3}{|l|}{ ANOVA Summary: } \\
\hline Mean Square & 559.926 & 176.659 \\
\hline F-value & 132.341 & 53.371 \\
\hline Significance level & 0.000 & 0.000 \\
\hline \multicolumn{3}{|l|}{ Coefficients } \\
\hline Cost Efficiency & 4.975 & 3.918 \\
\hline t value & 4.525 & 3.91 \\
\hline Significance level & 0.000 & 0.000 \\
\hline Revenue Efficiency & 4.823 & 1.980 \\
\hline t value & 3.090 & 0.878 \\
\hline Significance level & 0.009 & 0.361 \\
\hline City & 3.711 & 1.094 \\
\hline t value & 10.379 & 2.856 \\
\hline Significance level & 0.000 & 0.004 \\
\hline Local & 2.369 & 0.26 \\
\hline t value & 14.992 & 1.553 \\
\hline Significance level & 0.000 & 0.121 \\
\hline
\end{tabular}

\section{Summary and Implications}

The results in descriptive statistics lend support to our understanding. In recent years, when e-banking is known to be developed, Japanese banking sector experience higher cost and revenue efficiencies than in the last decade of 20 th century when e-banking was not a norm of the banking sector yet.

Operating efficiency measures are significant drivers of perceptions of banking risk. The Japanese banks in recent years have significantly lower levels of perceived riskiness than the banks in past years. Evidence is provided that lower banking risk is associated with higher cost and revenue efficiencies. These factors are significant risk determinants in both regression results, but their contribution to the explanation of risk scores is greater for current data set (2000-2005). This supports the argument that the riskiness of the banking industry might be reduced somewhat if a focus is directed to operating efficiency and then to e-banking.

This is not to say that operating efficiency measures are the only drivers of banking risk. Banking risk is also driven by economic, bank balance sheet and political factors that have not been captured in this study. Nevertheless, the study shows that efficiency measures are significant drivers of banking risk scores.

The literature appears to indicate that these efficiency measures are also drivers of e-banking. It provides a degree of support to our hypothesis that lower banking risk could be driven by efficient e-banking. Further research is necessary to establish empirically (rather than to rely on the literature) that e-banking may be effectively measured by the proportion of bank expenditures that are devoted to e-commerce. This is a subject of future research.

Based on this study, we recommend developing countries to consider adopting e-banking model. Continued economic and banking reform is of course a prerequisite so that adapted e-banking models can more easily be 
implemented. This will involve the ongoing reform of legal, commercial, banking and finance and bureaucratic infrastructures so that the establishment of Internet and thus e-banking infrastructures can take place.

The literature supports the notion that banks are unable to properly implement e-banking without a strong Internet infrastructure (and without partnerships with Internet delivery companies).

If with further extensive research of other developed countries shows that banking risk can be minimized through efficient Internet-banking and if banks in emerging economies adopt this model, path will be opened for economic benefits to accrue both within each country and globally.

\section{References}

Aliyu, A.A. \& Tasmin, R. (2012). The Impact of Information and Communication Technology on Banks Performance and Customer Service Delivery in the Banking Industry. International Journal of Latest Trends in Finance \& Economic Sciences. 2(1), 80-90.

Bourke, P. \& Shanmugam, (1990). Risks in international lending. in: An introduction to bank lending. Chapter 12, (Addison-Wesley, Sydney).

Cline, K. (1999a). Rules of the game. Banking Strategies. 75(5), 82-88.

Cline, K. (1999b). Rush for position. Banking Strategies. 75(5), 22-30.

Ekwueme, C.M., Egbunike, P.A. \& Okoye, A. (2012). An Empirical Assessment of the operational efficiency of electronic banking: Evidnce of Nigerian banks. Review of Public Administration \& Management. 1(2), 119-149.

Esser, J. (1999). Internet banking is a virtual necessity. Credit Union Magazine. 65(10), 35-36.

FISC Report. (2005). Center for Financial Industry Information Systems. Japan.

Gautam, V. (2012). Measuring the Impact of New Technologies through Electronic-Banking on Profitability of Banks: Evidence form Indian Banking Industry. Romanian Journal of Marketing. (3), 20-26.

Goodman, M. (1999). Checking the foundation of banking sites. Banking Systems and Technology. 36(10), 3-14.

Jaleshgari, R.P. (1999a). Document Trading Online. Information Week, (755), 136.

Jaleshgari, R.P. (1999b). Beyond Y2K: Better Systems Integration. Information Week, (754), 99-110.

Laeven, L. (1999). The efficiency of the Thai banking system. World Bank.

Maddala, G.S. (1992). Introduction to Econometrics. 2nd Ed, Prentice Hall Inc.

Mai, H. (2012). IT in banks: what does it cost? Deutsche Bank Research. Germany.

Menendez, M. (1999). The Internet is not a business category but a medium for business. Moodys' Press Release.

Moodys'. (1999a). International credit opinions, Moodys' Investors Service. January.

Moodys'. (1999b). Analytical framework for the rating of banks. E-mail press release.

Moodys'. (1999c). European banks to see more consolidation and competition. E-mail press release.

Nolan, S. (1999). E-banks in a box. Journal of Lending and Credit Risk Management. 82(2), 18-22.

O'Connell, R. (2000). Major US banks well positioned to compete with Internet banks. Moodys's Investors Service. Press release January.

Salehi, M. \& Alipour, M. (2010). E-banking in Emerging Economy: Empirical Evidence of Iran. International Journal of Economics and Finance. 2(1) 1-9. http://dx.doi.org/10.5539/ijef.v2n1p201

Simpson, J. (1999). Country risk, International Banking Risk and Economic Development. Unpublished Ph.D. Thesis, University of Western Australia.

Simpson, J. (2002). The impact of the Internet in banking: observations and evidence from developed and emerging markets. Telematics and Informatics. 19(4), 315-330. http://dx.doi.org/10.1016/S0736-5853(01)00019-3

Statistics Brain. (2014). Onlin/mobile banking statistic. Pew Research Center, Federal Reserve. http://www.statisticbrain.com/online-mobile-banking-statistics/

Streeter, W.W. (1999a). If it ain't broke, cannibalise it. ABA Banking Journal. 91(9), 15.

Streeter, W.W. (1999b). Sobering views from the e-commerce space. ABA Banking Journal. 91(9), 7-10.

Sweeney, P. (1999). Cyber crimes' looming threat. Banking Strategies. 75(4), 54-59. 
Theodore, S. (2000). Online winds of change: European banks enter the age of the Internet. Moodys' Investors Service, February.

Turton, J. (1999). E-procurement can save you time and money. Corporate Finance. (177), 21-22.

Xiusheng, L. \& Wanhua, Q. (2013). Study of Efficiency Measure of Online Banking Based on DEA Models. Taking Three Commercial Banks as Examples. International Journal of Digital Content Technology \& its Applications. 7(3), 389-394. http://dx.doi.org/10.4156/jdcta.vol7.issue3.49

Yamori, N., K. Harimaya \& Y. Asai. (2005). Recent development of information technology in Japanese banks. Nagoya University, Economic Research Center, Discussion Paper, E05-3.

Notes

Note 1. Model specification is based upon Simpson (2002)

Note 2. See Maddala (1992) for further discussion on VIF. 